\title{
The novel nitric oxide donor PDNO attenuates ovine ischemia-reperfusion induced renal failure
}

\author{
Kristofer F. Nilsson ${ }^{1,2}$, John Sandin ${ }^{2}$, Lars E. Gustafsson ${ }^{2}$ and Robert Frithiof $f^{2,3^{*}}$ (D)
}

\author{
* Correspondence: \\ robert.frithiof@surgsci.uu.se \\ ${ }^{2}$ Department of Physiology \& \\ Pharmacology, Karolinska Institutet, \\ Stockholm, Sweden \\ ${ }^{3}$ Department of Surgical Sciences, \\ Section of Anesthesia and Intensive \\ Care, Uppsala University, Uppsala, \\ Sweden \\ Full list of author information is \\ available at the end of the article
}

\begin{abstract}
Background: Renal ischemia-reperfusion injury is a common cause of acute kidney injury in intensive care and surgery. Recently, novel organic mononitrites of 1,2propanediol (PDNO) were synthesized and shown to rapidly and controllably deploy nitric oxide in the circulation when administered intravenously. We hypothesized that intravenous infusion of PDNO during renal ischemia reperfusion would improve post-ischemic renal function and microcirculation.
\end{abstract}

Methods: Sixteen sheep were anesthetized, mechanically ventilated, and surgically instrumented. The left renal artery was clamped for $90 \mathrm{~min}$, and the effects of ischemia were studied for a total of $8 \mathrm{~h}$. Fifteen minutes prior to the release of the clamp, intravenous infusions of PDNO $(n=8)$ or vehicle (1,2 propanediol + inorganic nitrite, $n=8)$ were initiated $(180 \mathrm{nmol} / \mathrm{kg} / \mathrm{min}$ for $30 \mathrm{~min}$, thereafter $60 \mathrm{nmol} / \mathrm{kg} / \mathrm{min}$ for the remainder of the experiment).

Results: Renal artery blood flow, cortical and medullary perfusion, and diuresis and creatinine clearance decreased in the left kidney post ischemia. However, in the sheep treated with PDNO, diuresis and creatinine clearance in the left kidney were significantly higher post ischemia compared to vehicle-treated animals $(1.7 \pm 0.5$ vs $0.7 \pm 0.3 \mathrm{ml} / \mathrm{kg} / \mathrm{h}, p=0.04$ and $7.5 \pm 2.1 \mathrm{vs} 1.7 \pm 0.6 \mathrm{ml} / \mathrm{min}, p=0.02$, respectively). Left renal medullary perfusion and oxygen uptake were higher in the PDNO group (73 \pm 9 vs $37 \pm 5 \%$ of baseline, $p=0.004$ and $2.6 \pm 0.4$ vs $1.6 \pm 0.3 \mathrm{ml} / \mathrm{min}, p=0.02$, respectively). PDNO significantly increased renal oxygen consumption and reduced the oxygen utilization for sodium reabsorption ( $p=0.03$ for both). Mean arterial blood pressure was significantly reduced by PDNO ( $83 \pm 3$ vs $94 \pm 3 \mathrm{mmHg}, p=0.02$ ) but was still within normal limits. Total renal blood flow was not affected, and there were no signs of increased blood methemoglobin concentrations or tachyphylaxis.

Conclusions: The novel nitric oxide donor PDNO improved renal function after ischemia. PDNO also prevented the persistent reduction in medullary perfusion during reperfusion and improved renal oxygen utilization without severe side effects.

Keywords: Kidney, Microcirculation, Sheep, Renal oxygen consumption, Nitrites, Acute kidney injury, AKI 


\section{Background}

Acute kidney injury (AKI) entails an increased risk of mortality and later development of chronic kidney disease in both critically ill and surgical patients [1, 2]. Originally, reduced blood flow has been overestimated as a cause of AKI, especially in sepsis [3]. Still warm ischemia is most likely a central component in the pathogenesis of AKI during prolonged hypotension, hypovolemia, and when blood flow is disrupted during cardiovascular events or vascular surgery [4]. Inadequate perfusion causes a mismatch in oxygen supply/demand in the renal tissue and scants removal of metabolic waste products, which result in injury and necrosis of renal tubular cells [5]. Ischemia also causes lingering vascular effects, including endothelial dysfunction, increased vascular tone, and a dysfunctional microcirculation, which further diminish renal function even if blood flow returns [6-8]. Several of these effects have been related to the release of free oxygen radicals [9].

Nitric oxide (NO) has been implicated on several stages in the pathogenesis of ischemic AKI. One hypothesis suggests that in renal ischemia-reperfusion injury (IRI), there is a reduction in endothelial nitric oxide synthase (NOS) but an increase in inducible NOS. This combination contributes to inflammation and vasoconstriction during reperfusion [10]. $\mathrm{NO}$ is a potent vasodilator as well as a free oxygen scavenger, which in theory would be beneficial post ischemia. However, treatment with exogenous NO in experimental renal IRI has resulted in contrasting results including beneficial, detrimental, or no effects on renal function [11-15]. This could be model specific and related to species but also coupled to the NO donor used.

Recently, a mixture of novel organic mononitrites of 1,2-propanediol was synthesized, chemically characterized, and shown to be an efficacious vasodilator treatment in experimental pulmonary hypertension [16]. The advantages of this composition of organic nitrites include very rapid deployment of NO in the tissue, easily controllable intravenous use, and minor development of methemoglobin. The fast donation of NO is theoretically important during initial reperfusion since the treatment may reach and have effect in the microcirculation before vascular dysfunction occurs. Furthermore, it contributes to a short plasma half-life of the compound, which in turn enables rapid control of the physiological response by adjusting the intravenous infusion rate of PDNO.

Based on these properties of PDNO and the pathophysiology of renal IRI, we hypothesized that intravenous infusion of PDNO would improve renal function and microcirculation after renal ischemia, without causing methemoglobinemia or severe systemic hypotension.

\section{Methods}

The experimental protocol was approved in advance by the regional animal ethics committee in Stockholm, Sweden and adheres to the Laboratory Animal Care formulated by the National Society for Medical Research and the US National Academy of Sciences.

\section{Animals and surgical preparation}

Adult cross-bred ewes $(n=16)$ weighing $61 \pm 2 \mathrm{~kg}$ were used. They were housed individually in cages with free access to water. Twice a day, they were fed hay and $75 \mathrm{~g}$ 
commercial pellets with the addition of $6 \mathrm{~g} \mathrm{NaCl}$. All experiments started between 08.30 and $09.30 \mathrm{~h}$, approximately $1-2 \mathrm{~h}$ after the morning feed.

Surgery was performed aseptically and under general anesthesia as previously described [17]. Anesthesia was induced by an intravenous injection of sodium thiopental $(15 \mathrm{mg} / \mathrm{kg})$ in $0.9 \%$ saline. After endotracheal intubation, surgical anesthesia was maintained by isoflurane (2.1-2.3\% end-tidal concentration) in an $\mathrm{O}_{2} /$ air mixture $(30 \% / 70 \%)$ from a respirator, intravenous midazolam $(5 \mathrm{mg}$ in $50 \mathrm{ml}$ isotonic $\mathrm{NaCl}, 0.05 \mathrm{mg} / \mathrm{kg} / \mathrm{h}$ ), and intravenous administration of fentanyl $(50-100 \mu \mathrm{g})$. Tidal volumes were kept at $10 \mathrm{ml} / \mathrm{kg}$, and the respiratory rate was adjusted to keep end-tidal $\mathrm{CO}_{2}$ between 5.1 and $5.9 \%$. The left carotid artery was surgically dissected and cannulated for blood sampling and measurement of arterial blood pressure. The skin and underlying tissue layers were enclosed with sutures. The sheep were prepared with a pulmonary artery catheter for measurement of cardiac output $(\mathrm{CO})$ and central venous catheters as previously described $[18,19]$. A flank incision was made from the last rib to the iliac crest to get a retroperitoneal approach to the aorta, left renal vein, left renal artery, and left kidney. A ligature was placed around the left renal artery at its departure from the aorta, which was later used as a vascular occluder to induce renal ischemia. Thereafter, an ultrasonic flow probe (4SB Transonic System Inc, NY, USA) was placed around the left renal artery distal to the ligature. The left renal vein was cannulated close to vena cava inferior, and a catheter was advanced in the vessel until it was located $5 \mathrm{~mm}$ from the kidney. This catheter was later used for renal venous blood sampling. The left ureter was then localized, cannulated, and ligated distally for urine collection from the left kidney. Urine from the right kidney was collected from the urine bladder via a retention catheter. Finally, a laser Doppler probe $(0.25 \mathrm{~mm}$ fiber separation, $780 \mathrm{~nm}$ wavelength; Perimed AB, Järfälla, Sweden) was sutured to the surface of the kidney for cortical measurements, and a needle laser Doppler probe $(0.15 \mathrm{~mm}$ fiber separation, $780 \mathrm{~nm}$ wavelength) was inserted 10-12 mm into the kidney for medullary measurements.

\section{Hemodynamic recordings}

Arterial blood pressure was measured via a pressure transducer (DPT-6003, PVB Medizin Technik, BMBH, Kirchseen, Germany). Signals from the thermodilution pulmonary artery catheter were fed into a Vigilance ${ }^{\bullet}$ Monitor (Baxter Healthcare Corporation, CA, USA) where the CO was calculated by three consecutive injections $(10 \mathrm{ml})$ of ice-cooled isotonic saline. The flow probe was connected to a Transonic T208 two channel flowmeter, and left renal volume blood flow was recorded continuously. Continuous online data acquisition was achieved by using the MP150/Acknowledge 3.9.1 system (BIOPAC Systems; Goleta, CA, USA) with a sampling rate of $200 \mathrm{~Hz}$. The two laser Doppler probes were calibrated according to the manufacturer's instructions and connected to a Periflux 5001 base unit (780 nm wavelength, $15 \mathrm{kHz}$ band width, 0.2-s time constant; Perimed AB).

\section{Experimental protocol}

The experimental protocol is outlined in Fig. 1. After surgery, the sheep were allowed to recover for $60 \mathrm{~min}$, during which urine was collected. Ischemia was then induced by complete clamping of the left renal artery via the surgically implanted ligature. The 


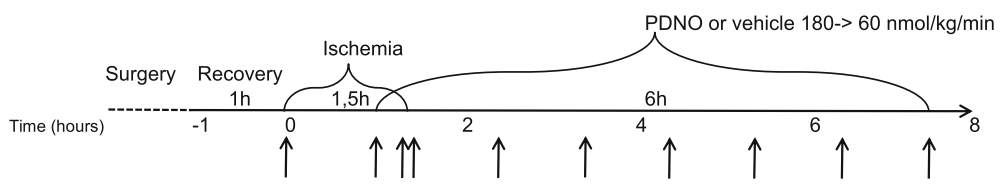

Fig. 1 Schematic diagram illustrating the experimental protocol. After surgery, the sheep recovered for $60 \mathrm{~min}$. Renal ischemia was caused by clamping of the left renal artery for $90 \mathrm{~min}$. Fifteen minutes prior to the release of the clamp, intravenous infusions of either the organic mononitrites of 1,2-propanediol (PDNO) or vehicle (1,2-propanediol + inorganic nitrite) were commenced. The infusions continued for $6 \mathrm{~h}$, during which renal function was monitored. The arrows indicate times for measurements and blood-/urine-sampling performed at baseline, prior to treatment, prior and directly following the release of the clamp, and continuously every hour after treatment was started

effect of the clamp was confirmed by a cease in measured left renal blood flow. Ischemia continued for $90 \mathrm{~min}$ before the clamp was released. The reperfusion phase was followed for an additional $6 \mathrm{~h}$. Sheep were randomized to either receive an infusion of PDNO (17 mM PDNO, $11 \mathrm{mM}$ inorganic nitrite, and 25\% 1,2-propanediol $[v / v]$ in saline, $n=8)$ or vehicle (28 mM inorganic nitrite and 25\% 1,2-propanediol $[v / v]$ in saline $n=8)$. The infusion was commenced $15 \mathrm{~min}$ prior to the release of the clamp at a rate of $180 \mathrm{nmol} / \mathrm{kg} / \mathrm{min}$ of PDNO in the PDNO group. After $30 \mathrm{~min}$, the infusion rate was reduced to $60 \mathrm{nmol} / \mathrm{kg} / \mathrm{min}$ of PDNO in the PDNO-treated animals and was kept at this rate for the remainder of the experiment. The infusion of vehicle in the vehicletreated animals was done at similar infusion rates in $\mathrm{ml} / \mathrm{kg} / \mathrm{h}$ as in the PDNO group. Thus, the vehicle-treated animals received an identical load of nitric oxide species in the form of inorganic nitrite that the PDNO group received in PDNO and inorganic nitrite as well as an identical load of 1,2-propanediol. The organic mononitrites of 1,2propanediol was synthesized as previously described, and the inorganic nitrite content in the PDNO solution was a consequence of the method of synthesis [16]. Blood samples were taken from the left renal vein, carotid artery, and jugular vein at baseline, prior to treatment, prior and directly following the release of the clamp, and every hour after treatment was started. Urinary output was measured, and urine samples from both kidneys were collected at baseline, after $90 \mathrm{~min}$ and thereafter every second hour.

Fluid volume support was administered as intravenous glucose $(50 \mathrm{mg} / \mathrm{ml}$ at $1 \mathrm{ml} /$ $\mathrm{kg} / \mathrm{h})$ and Ringer's acetate solution $(7 \mathrm{ml} / \mathrm{kg} / \mathrm{h})$. The latter entails a substantial loading of fluids and electrolytes that may be considered protective during I/R. Both groups received the same fluid volume support in order not to influence the results of PDNO treatment.

\section{Blood, plasma, and urine analyses}

The venous blood was portioned into pre chilled tubes with EDTA as anticoagulant and centrifuged at $+4^{\circ} \mathrm{C}(3000 \mathrm{rpm})$. Plasma and urine aliquots were stored at $-20{ }^{\circ} \mathrm{C}$ until assayed for creatinine according to the Jaffe method (Synchron LX, Beckman Instruments, Richmond, CA). Other portions of plasma and urine were taken for determination of sodium concentrations (IL 943 flame photometer; Instrumentation Labs, Italy). The carotid and renal venous blood samples were used for immediate arterial blood gas analyses performed on an ABL 700 (Radiometer, Copenhagen, Denmark). 


\section{Calculations and statistical analysis}

Cardiovascular parameters were averaged offline. Creatinine clearance was calculated as [(Urine flow $\times$ Urine creatinine concentration)/plasma creatinine concentration] and used as an estimate of GFR. Renal oxygen consumption $\left(\mathrm{QO}_{2}\right)$ was calculated as [Renal blood flow $\times 1.34 \times$ hemoglobin concentration $\times$ (arterial blood oxygen saturation renal vein blood oxygen saturation)]. The oxygen consumed for sodium reabsorption was calculated as [renal oxygen uptake/(plasma sodium concentration $\times$ GFR - urinary sodium concentration $\times$ urine output)].

All statistical calculations were performed using Statistica 13 (Dell Inc., Tulsa, OK, USA), and the graphs were created with Sigma Plot 13 (SPSS Inc., Chicago, IL, USA). Data are expressed as mean \pm standard error of the mean (SEM). The oxygen consumed for sodium reabsorption values and urine output were transformed to follow a normal distribution by taking the natural logarithm of the raw data. Changes in parameters over time were analyzed according to a two-way repeated measures ANOVA, followed by pairwise planned comparisons. The significance level was set at $p \leq 0.05$.

\section{Results}

All animals survived the experiment. $\mathrm{CO}$ and heart rate did not change significantly during the experiment (Table 1). Mean arterial blood pressure (MAP) was immediately slightly reduced by PDNO and remained significantly lower compared to vehicle (83 \pm 3 vs $94 \pm 3 \mathrm{mmHg}, p=0.02$, after $6 \mathrm{~h}$ and $15 \mathrm{~min}$ of infusion, Table 1$)$. There were no signs of tachyphylaxis with regards to the MAP response. In the vehicle-treated animals, methemoglobin levels were $3.4 \pm 0.1 \%$ at baseline and $3.4 \pm 0.2 \%$ at the end of the experiment. In the PDNO-treated sheep, the corresponding values were $3.3 \pm 0.1 \%$ and $3.6 \pm 0.1 \%$, respectively.

\section{Renal function}

Urine output and creatinine clearance were measured separately in each kidney. Both variables were reduced to zero in the left kidney in response to clamping of the left renal artery (Fig. 2a). There was a tendency to a slight but passing reduction in urine output also in the right kidney but neither urine output nor creatinine clearance changed significantly over time in the right kidney (Fig. 2a). Urine output from the left kidney increased post ischemia to a higher level in the sheep subjected to PDNO compared to vehicle ( $p=0.04$, Fig. 2a). The same effect was seen in the GFR estimation as the PDNO-treated sheep had a significantly higher creatinine clearance at the end of the experiment ( $p=0.02$, Fig. 2a). Plasma potassium increased from $3.5 \pm 0.1 \mathrm{mmol} / \mathrm{L}$ at baseline to $4.0 \pm 0.1 \mathrm{mmol} / \mathrm{L} 6 \mathrm{~h}$ post ischemia, with no intergroup differences.

\section{Renal hemodynamics}

Left renal blood flow was reduced to zero during clamping. After the release of the clamp, renal blood flow initially increased rapidly and had returned to near baseline levels at the end of the experiment (Fig. 3a). There were no significant effects of PDNO on total renal blood flow compared to vehicle. As expected, left renal perfusion ceased during the ischemia period but when renal blood flow returned, medullary perfusion increased to a higher level in the PDNO group compared to the vehicle group 


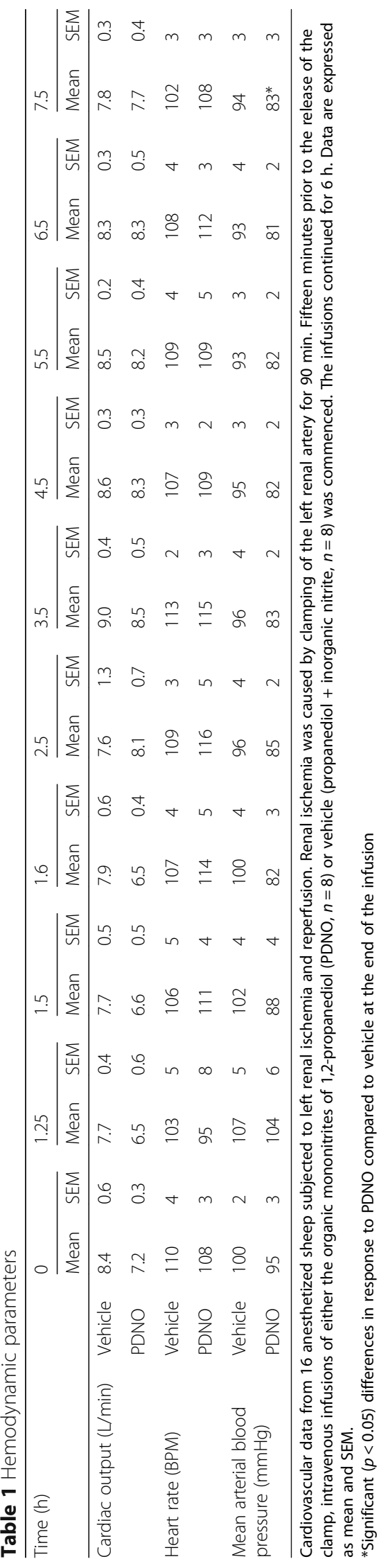




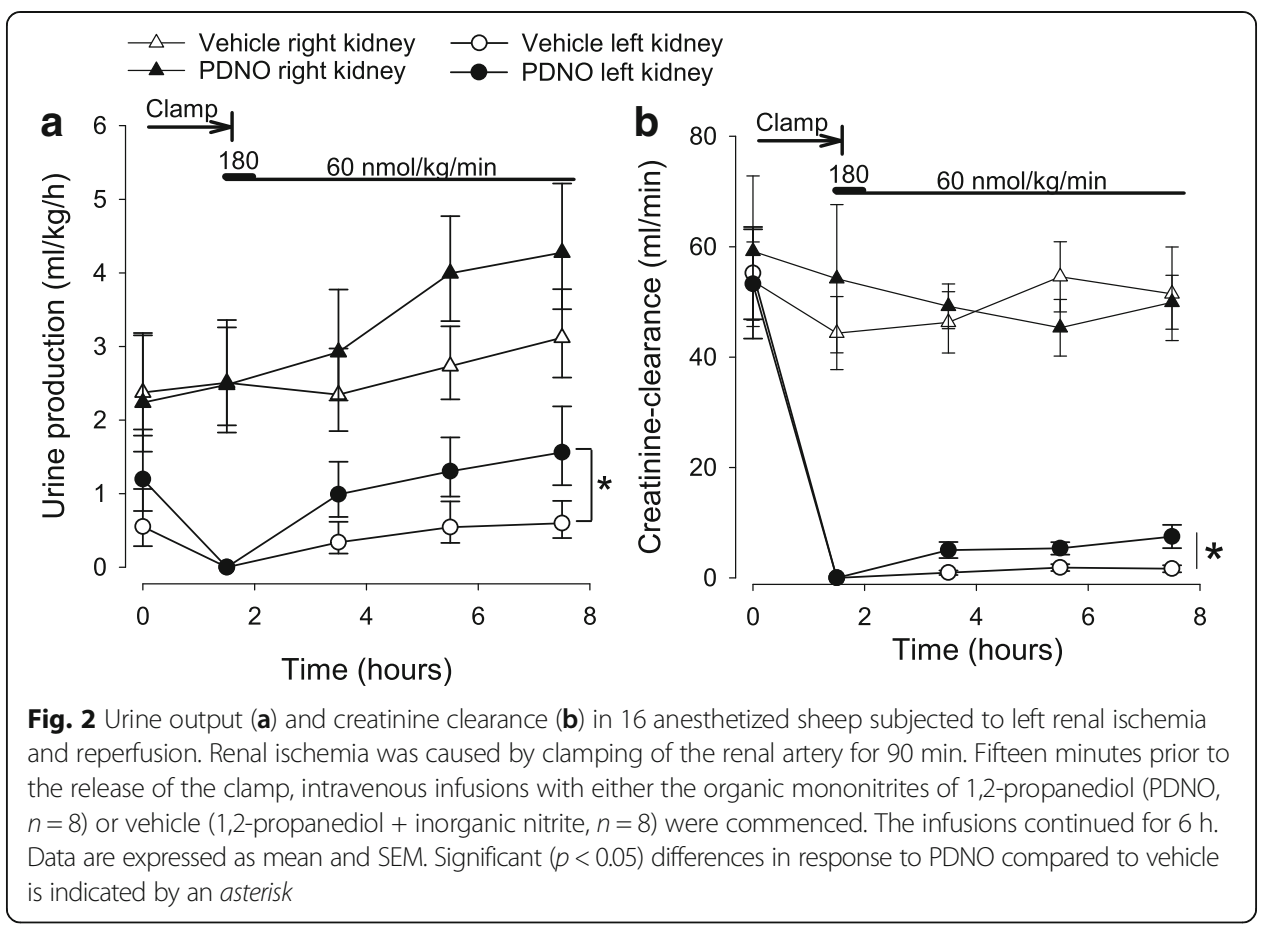

$(p=0.002$, Fig. $3 \mathrm{~b})$. There was a similar tendency also in cortical microcirculatory perfusion, but this effect was not statistically significant ( $p=0.08$, Fig. $3 c)$.

\section{Renal metabolism}

Left renal $\mathrm{QO}_{2}$ was similar in both groups at baseline. After the ischemic period, left renal $\mathrm{QO}_{2}$ was reduced in animals treated with $\mathrm{PDNO}$ and vehicle. However, although baseline levels were never reached, left renal $\mathrm{QO}_{2}$ slowly recovered during reperfusion. This effect was more pronounced in the PDNO group, resulting in a significantly higher left renal $\mathrm{QO}_{2}$ at the end of the experiment ( $p=0.03$, Fig. 4a). Renal tubular integrity can be estimated by calculating the amount of oxygen that is needed for the reabsorption of sodium. An increase in required oxygen indicates that sodium leaks back into the urine after reabsorption or that the active transport of sodium is damaged. In these experiments, the ratio between renal $\mathrm{QO}_{2}$ and reabsorbed sodium increased in response to ischemia and reperfusion indicating that the renal tubuli were damaged. However, PDNO attenuated this effect and after $6 \mathrm{~h}$ of reperfusion, the amount of oxygen required for sodium reabsorption was significantly lower in the PDNO-treated animals compared to vehicle ( $p=0.03$, Fig. $4 \mathrm{~b})$.

\section{Discussion}

The most important finding in the current study was that the novel NO donor PDNO improved renal function, as estimated by urine output and creatinine clearance (Fig. 2), compared to a vehicle containing comparable amounts of inorganic nitrite. This was achieved without massive vasodilation and thus, although reduced, arterial blood pressure was maintained within limits not requiring vasopressor support. Furthermore, a $6 \mathrm{~h}$ infusion of PDNO did not cause methemoglobinemia. 

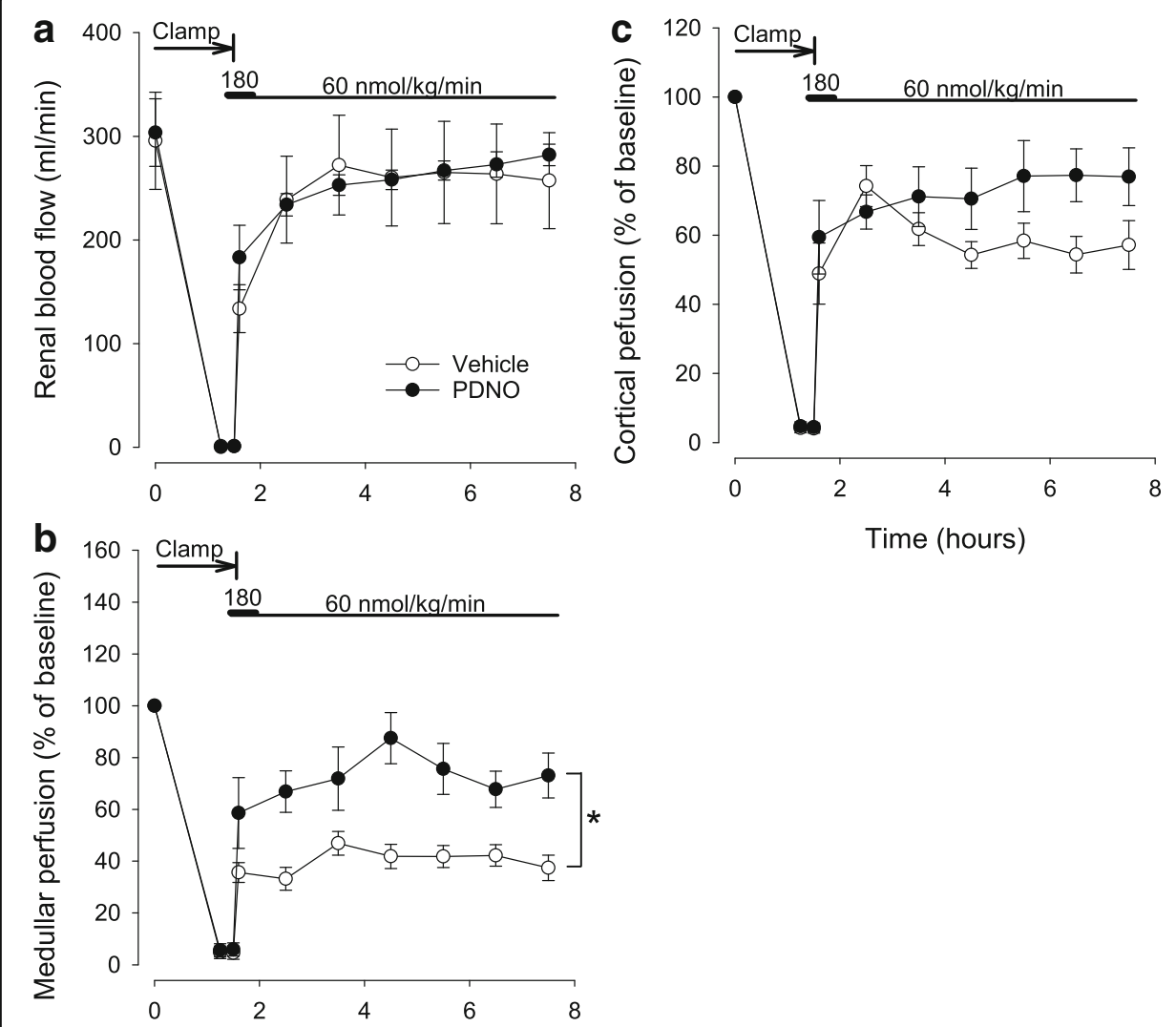

Fig. 3 Total left renal blood flow (a) as well as left renal medullar (b) and cortical perfusion (c) as estimated by laser Doppler in 16 anesthetized sheep subjected to left renal ischemia and reperfusion. Renal ischemia was caused by clamping of the left renal artery for 90 min. Fifteen minutes prior to the release of the clamp intravenous infusions of either the organic mononitrites of 1,2-propanediol (PDNO, $n=8)$ or vehicle (1,2-propanediol + inorganic nitrite, $n=8$ ) were commenced. The infusions continued for $6 \mathrm{~h}$. Data are expressed as mean and SEM. Significant $(p<0.05)$ differences in response to PDNO compared to vehicle is indicated by an asterisk

Renal IRI is the result of direct ischemia causing acute tubular necrosis which subsequently leads to decreased glomerular filtration pressure and tubular obstruction [20]. In addition, reperfusion brings microcirculatory dysfunction and disturbed oxygen handling $[21,22]$. All together, this gives rise to the decrease in GFR and urine output which is the clinical hallmarks of AKI [23]. The fact that PDNO was able to improve both these variables (Fig. 2) in a clinically relevant large animal model is important as it, for the first time, indicates that this new NO donor could be a future tool in the treatment of AKI induced by ischemia reperfusion.

Blood flow to the kidney is normally approximately $20 \%$ of $\mathrm{CO}$ and kept within relatively strict limits due to autoregulation [24]. The absolute majority of renal blood flow is directed to the renal cortex whereas the renal medulla only receives a fraction of the total renal blood flow. The high metabolic activity in combination with the relatively low blood supply makes the renal medulla susceptible to reductions in oxygen delivery [25]. In IRI, perfusion in the renal medulla has been shown to be persistently depressed $[22,26]$. In the current experiments, total renal blood flow rapidly returned to near baseline values (Fig. 3a). However, in the vehicle group renal medullary perfusion only reached approximately $40 \%$ of baseline levels on a group level (Fig. 3b). Previous investigations indicate that this may be due to trapping of red blood cells, vasoconstriction, 

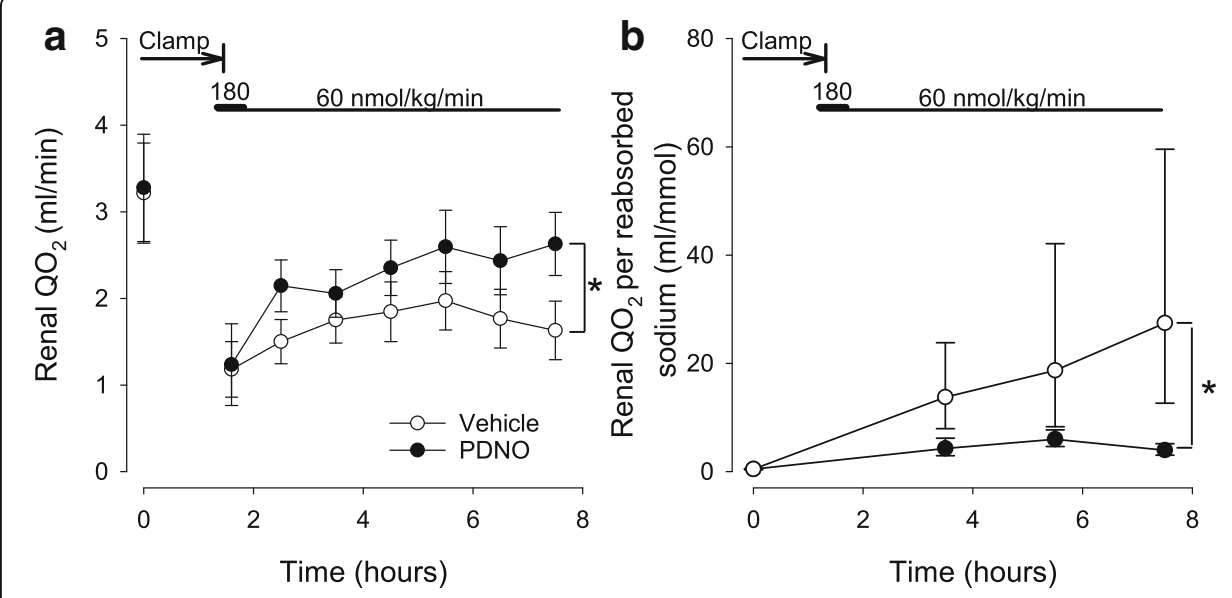

Fig. 4 Renal oxygen consumption $\left(\mathrm{QO}_{2}\right.$, a) and renal $\mathrm{QO}_{2}$ per reabsorbed sodium (b) in 16 sheep subjected to renal ischemia and reperfusion. Renal ischemia was caused by clamping of the renal artery for $90 \mathrm{~min}$. Fifteen minutes prior to the release of the clamp intravenous treatment with either 1,2-propanediol nitric oxide (PDNO, $n=8$ ) or vehicle (propanediol + inorganic nitrite, $n=8$ ) was commenced. The treatment continued for 6 h. Data are expressed as mean and SEM. Significant $(p<0.05)$ differences in response to PDNO compared to vehicle is indicated by an asterisk

swelling of the endothelium and/or tubular obstruction [22, 26-28]. PDNO effectively improved medullary perfusion immediately after blood flow to the kidney returned (Fig. 3b). The rapid effect is in line with the ability of PDNO to swiftly deploy NO in the tissue, conceivably before some of the detrimental effects of reperfusion occur. NO acts as a vasodilator counteracting the ensuing vasoconstriction caused by endothelin1 , adenosine, and angiotensin II $[29,30]$. It also scavanges free oxygen radicals which are believed to impair renal microcirculation in IRI [31]. In renal IRI, the vasorelaxing effect of acetylcholine is impaired [32] and NO production is depressed due to endothelial injury and reduced NOS activity [33-35]. Furthermore, it has been suggested that ROS produced during reperfusion react with and downregulate the bioavailability of NO causing medullary vasoconstriction [36]. Dysregulation of renal NO content thus likely contributes to vasoconstriction and hypoxia but could theoretically be counteracted by the exogenous NO donated by PDNO.

Renal oxygen handling is severely impaired in renal IRI [21,37]. In the sheep subjected to IRI in this study, renal $\mathrm{QO}_{2}$ was significantly reduced post ischemia (Fig. 4a). Oxygen uptake in the kidney is high compared to other organs; only the heart has higher $\mathrm{QO}_{2}$ per gram tissue [38]. The most energy-consuming process is sodium reabsorption in the proximal tubule and the medullary thick ascending limb, and this transport is tightly coupled to GFR [39]. Thus, the reduced renal $\mathrm{QO}_{2}$ seen here may be due to major tubular cell death lowering oxygen requirements or to the reduced GFR, as estimated by creatinine clearance. An additional explanation is that the diminished renal $\mathrm{QO}_{2}$ post ischemia is related to reduced oxygen delivery caused by the impaired medullary perfusion (Fig. 3b). PDNO effectively improved renal $\mathrm{QO}_{2}$ (Fig. 4a), and based on the previous discussion, this is likely due to that NO prevented acute tubular necrosis, improved GFR, and/or renal perfusion.

At baseline, the sheep consumed approximately $0.5 \mathrm{ml}$ oxygen per millimole of reabsorbed sodium which is slightly less compared to man [37]. After ischemia/reperfusion, this increased to an average of $27.4 \mathrm{ml}$ oxygen per millimole of reabsorbed sodium in 
the vehicle group. A possible mechanism for this is that the renal tubular cells loose the integrity of the tight junctions due to ischemia and that NaK-ATPase redistributes to the apical membrane of tubular cells [40]. This in turn causes backward leakage of the reabsorbed sodium to the tubular lumen and faulty active transport of sodium from the intracellular domain to the urine [41]. If the function of the NaK-ATPase is intact, this will lead to increased oxygen-dependent transport of sodium without effective reabsorption. The PDNO-treated sheep displayed a significantly lower ratio between consumed oxygen and reabsorbed sodium, perhaps indicating less ischemic injury to tubular function.

NO is a key molecule in the control of renal oxygen supply, both as a vasodilator but also as regulator of oxidative metabolism [42]. An additional explanation for the increased oxygen utilization for sodium reabsorption that also is in line with the positive effect of NO deployment by PDNO is the decreased renal NO concentration previously discussed. Like oxygen, NO enters mitochondrial respiration and a decreased NO concentration augments oxygen consumption [43]. This is believed to play an important role in chronic kidney disease [44]. In instrumented conscious dogs, inhibition of NO production significantly increased the renal $\mathrm{QO}_{2} /$ sodium reabsorption ratio [42]. Furthermore, recent data showed that the ROS-scavanger tempol prevented a fall in NO levels and improved tissue oxygen concentration after renal ischemia [45]. Taken together, this supports the idea that PDNO rapidly replaces pathologically decreased renal NO levels to improve oxygenation in the current experimental setup.

Methemoglobin reduces the oxygen carrying capacity of erythrocytes and impairs oxygen off-loading to the tissues [46]. Methemoglobinemia is a known side effect of both intravenous and inhalational NO treatments, most often after high doses have been administered [47, 48]. Our results indicate that PDNO can be infused intravenously at a rate sufficient for beneficial systemic effects without causing methemoglobinemia.

There are several limitations to this study that needs to be acknowledged. We aimed to use a model that mimics the clinical situation seen in renal IRI using fluidresuscitated large animals. Still, results from animal models are not directly applicable to the human clinical scenario. What is most noteworthy is that many cases of IRI do not develop after a short period of total absence of blood flow but are instead the result of a longer period of insufficient perfusion, such as prolonged hypotension or hypovolemia. The current model perhaps mostly resembles suprarenal artery vascular surgery, although the reduction in creatinine clearance in the left kidney is more pronounced compared to what is usually seen clinically. Although the amelioration in creatinine clearance in the PDNO-treated animals was statistically significant, the improvement in absolute numbers was minor. This finding might suggest that PDNO is not sufficiently effective to be of clinical interest. To indicate a relevant effect on GFR, future experimental studies need to demonstrate a greater magnitude of protection by PDNO. It remains to be determined if this could be achieved by investigating the drug in a model with less pronounced decrease in creatinine clearance induced by a shorter period of complete renal ischemia or a subtotal reduction in renal blood flow. Furthermore, renal histology was not compared between groups. Although renal dysfunction is not always coupled to structural damage [49], this could have added additional mechanistic insight into the effects of PDNO. Another limitation is related to PDNO treatment. We used 
pre-treatment, which is not always clinically possible, and we did not compare PDNO with another classic NO donor but with inorganic nitrite (the vehicle). Inorganic nitrite was included in the placebo vehicle since the synthesis of PDNO also forms a certain amount of inorganic nitrite in the solution [16]. The vehicle-treated group received a solution with $28 \mathrm{mM}$ of inorganic nitrite to achieve a similar load of nitric oxide species as the PDNO group (17 $\mathrm{mM}$ of PDNO and $11 \mathrm{mM}$ of inorganic nitrite). Previously, inorganic nitrite administration has been suggested to reduce myocardial and hepatic IRI in several animal models [50]. In contrast, intravenously administered inorganic nitrite was shown to exert no effect on renal IRI whereas topically applied inorganic nitrite improved renal function in renal IRI [51, 52]. From the present experiments, it is not possible to estimate the effects of inorganic nitrite on renal IRI since the vehicle in the control group also included inorganic nitrite. However, based on previous investigations in the kidney and other organs $[50,52]$, it is unlikely that the inorganic nitrite supply had detrimental effects on renal function in the present study. Clearly, the present data show that the organic nitrites are superior to inorganic nitrite in renal IRI at the doses used. Finally, the sheep used were anesthetized using isoflurane. This has previously been shown to aggravate renal vasoconstriction in endotoxemia-induced AKI [53]. However, this effect was attenuated with major fluid resuscitation and here renal blood flow reached levels comparable to the conscious state [54].

\section{Conclusions}

Our study demonstrated that the novel NO donor PDNO significantly improved renal function during ischemia reperfusion in a large-animal experimental model. This was accompanied by an improved renal medullary perfusion indicating a direct vasodilatory effect of PDNO on the microcirculation. PDNO also increased renal oxygen consumption which in combination with disrupted perfusion could be detrimental. However, a more effective oxygen handling, as indicated by a lower ratio between consumed oxygen and reabsorbed sodium, instead suggested less renal tubular damage and replacement of pathologically reduced renal NO levels in the PDNO group. The beneficial renal effects of PDNO in combination with absent methemoglobinemia, tachyphylaxis, or severe hypotension may make PDNO a potentially interesting NO donor for treatment of certain forms of renal IRI.

Funding

This study was supported by the Swedish Research Council (grant 523-2014-2569), Region Uppsala ALF Grants, Region Örebro County ALF Grants (agreement concerning research and education of doctors), the Swedish National Space Board, and Swedish Society for Medical Research.

The funding sources solely provided financial support and were not involved in any part of the conduct of the research.

Availability of data and materials

The datasets supporting the conclusions of this article are available upon request. Please contact robert.frithiof@surgsci.uu.se.

Authors' contributions

KFN, RF, and LEG designed the study. KFN, JS, and RF performed the experiments. KFN, JS, and RF analyzed and interpreted the data. RF drafted the manuscript. All authors participated in the critical revision of the manuscript, and all authors approved the final version to be submitted. 
Ethics approval

The experimental protocol was approved in advance by the regional animal ethics committee in Stockholm, Sweden and adheres to the Laboratory Animal Care formulated by the National Society for Medical Research and the US National Academy of Sciences.

\section{Publisher's Note}

Springer Nature remains neutral with regard to jurisdictional claims in published maps and institutional affiliations.

\section{Author details}

${ }^{1}$ Department of Cardiothoracic and Vascular Surgery, Faculty of Medicine and Health, Örebro University, Örebro, Sweden. ${ }^{2}$ Department of Physiology \& Pharmacology, Karolinska Institutet, Stockholm, Sweden. ${ }^{3}$ Department of Surgical Sciences, Section of Anesthesia and Intensive Care, Uppsala University, Uppsala, Sweden.

Received: 30 January 2017 Accepted: 26 May 2017

\section{Published online: 09 June 2017}

\section{References}

1. Rewa O, Bagshaw SM (2014) Acute kidney injury-epidemiology, outcomes and economics. Nat Rev Nephrol 10: 193-207

2. Heung M, Steffick DE, Zivin K, Gillespie BW, Banerjee T, Hsu CY, Powe NR, Pavkov ME, Williams DE, Saran R, Shahinian VB, Centers for Disease C, Prevention CKDST (2016) Acute kidney injury recovery pattern and subsequent risk of ckd: an analysis of veterans health administration data. Am J Kidney Dis 67:742-752

3. Langenberg C, Wan L, Egi M, May CN, Bellomo R (2006) Renal blood flow in experimental septic acute renal failure. Kidney Int 69:1996-2002

4. Sharfuddin AA, Molitoris BA (2011) Pathophysiology of ischemic acute kidney injury. Nat Rev Nephrol 7:189-200

5. Heyman SN, Rosenberger C, Rosen S (2010) Experimental ischemia-reperfusion: biases and myths-the proximal vs. distal hypoxic tubular injury debate revisited. Kidney Int 77:9-16

6. Molitoris BA, Sutton TA (2004) Endothelial injury and dysfunction: role in the extension phase of acute renal failure Kidney Int 66:496-499

7. Le Dorze M, Legrand M, Payen D, Ince C (2009) The role of the microcirculation in acute kidney injury. Curr Opin Crit Care 15:503-508

8. Conger JD, Robinette JB, Hammond WS (1991) Differences in vascular reactivity in models of ischemic acute renal failure. Kidney Int 39:1087-1097

9. Chatterjee PK, Cuzzocrea S, Brown PA, Zacharowski K, Stewart KN, Mota-Filipe H, Thiemermann C (2000) Tempol, a membrane-permeable radical scavenger, reduces oxidant stress-mediated renal dysfunction and injury in the rat. Kidney Int 58:658-673

10. Goligorsky MS, Brodsky SV, Noiri E (2004) NO bioavailability, endothelial dysfunction, and acute renal failure: new insights into pathophysiology. Semin Nephrol 24:316-323

11. Yates PJ, Hosgood SA, Nicholson ML (2012) A biphasic response to nitric oxide donation in an ex vivo model of donation after cardiac death renal transplantation. J Surg Res 175:316-321

12. Barakat N, Hussein AA, Abdel-Maboud M, El-Shair MA, Mostafa A, Abol-Enein H (2010) Ischaemia-reperfusion injury in renal transplantation: the role of nitric oxide in an experimental rat model. BJU Int 106:1230-1236

13. Nakajima A, Ueda K, Takaoka M, Yoshimi Y, Matsumura Y (2006) Opposite effects of pre- and postischemic treatments with nitric oxide donor on ischemia/reperfusion-induced renal injury. J Pharmacol Exp Ther 316:1038-1046

14. Tome LA, Yu L, de Castro I, Campos SB, Seguro AC (1999) Beneficial and harmful effects of L-arginine on renal ischaemia. Nephrol Dial Transplant 14:1139-1145

15. Johannes T, Mik EG, Klingel K, Goedhart PT, Zanke C, Nohe B, Dieterich HJ, Unertl KE, Ince C (2009) Effects of 1400W and/or nitroglycerin on renal oxygenation and kidney function during endotoxaemia in anaesthetized rats. Clin Exp Pharmacol Physiol 36:870-879

16. Nilsson KF, Lundgren M, Agvald P, Adding LC, Linnarsson D, Gustafsson LE (2011) Formation of new bioactive organic nitrites and their identification with gas chromatography-mass spectrometry and liquid chromatography coupled to nitrite reduction. Biochem Pharmacol 82:248-259

17. Fenhammar J, Rundgren M, Hultenby K, Forestier J, Taavo M, Kenne E, Weitzberg E, Eriksson S, Ozenci V, Wernerson A Frithiof R (2014) Renal effects of treatment with a TLR4 inhibitor in conscious septic sheep. Crit Care 18:488

18. Fenhammar J, Rundgren M, Forestier J, Kalman S, Eriksson S, Frithiof R (2011) Toll-like receptor 4 inhibitor TAK-242 attenuates acute kidney injury in endotoxemic sheep. Anesthesiology 114:1130-1137

19. Frithiof R, Mats R, Johan U, Stefan E, Hans H (2006) Comparison between the effects on hemodynamic responses of central and peripheral infusions of hypertonic $\mathrm{NaCl}$ during hemorrhage in conscious and isoflurane-anesthetized sheep. Shock 26:77-86

20. Lameire N, Van Biesen W, Vanholder R (2005) Acute renal failure. Lancet 365:417-430

21. Oostendorp M, de Vries EE, Slenter JM, Peutz-Kootstra CJ, Snoeijs MG, Post MJ, van Heurn LW, Backes WH (2011) MRI of renal oxygenation and function after normothermic ischemia-reperfusion injury. NMR Biomed 24:194-200

22. Yamamoto T, Tada T, Brodsky SV, Tanaka H, Noiri E, Kajiya F, Goligorsky MS (2002) Intravital videomicroscopy of peritubular capillaries in renal ischemia. Am J Physiol Renal Physiol 282:F1150-1155

23. Thomas ME, Blaine C, Dawnay A, Devonald MA, Ftouh S, Laing C, Latchem S, Lewington A, Milford DV, Ostermann M (2015) The definition of acute kidney injury and its use in practice. Kidney Int 87:62-73

24. Andersson A, Rundgren M, Kalman S, Rooyackers O, Brattstrom O, Oldner A, Eriksson S, Frithiof R (2012) Gut microcirculatory and mitochondrial effects of hyperdynamic endotoxaemic shock and norepinephrine treatment. $\mathrm{Br} J$ Anaesth 108:254-261

25. Epstein FH, Agmon Y, Brezis M (1994) Physiology of renal hypoxia. Ann N Y Acad Sci 718:72-81, discussion 81-72 
26. Olof P, Hellberg A, Kallskog O, Wolgast M (1991) Red cell trapping and postischemic renal blood flow. Differences between the cortex, outer and inner medulla. Kidney Int 40:625-631

27. Thiel G, de Rougemont D, Kriz W, Mason J, Torhorst J, Wolgast M (1982) The role of reduced medullary perfusion in the genesis of acute ischemic renal failure. Summary of a round-table discussion. Nephron 31:321-323

28. Sutton TA, Mang HE, Campos SB, Sandoval RM, Yoder MC, Molitoris BA (2003) Injury of the renal microvascular endothelium alters barrier function after ischemia. Am J Physiol Renal Physiol 285:F191-198

29. Bauerle JD, Grenz A, Kim JH, Lee HT, Eltzschig HK (2011) Adenosine generation and signaling during acute kidney injury. J Am Soc Nephrol 22:14-20

30. Pallone TL, Zhang Z, Rhinehart K (2003) Physiology of the renal medullary microcirculation. Am J Physiol Renal Physiol 284:F253-266

31. Ergin B, Kapucu A, Demirci-Tansel C, Ince C (2015) The renal microcirculation in sepsis. Nephrol Dial Transplant 30: 169-177

32. Conger JD, Robinette JB, Guggenheim SJ (1981) Effect of acetylcholine on the early phase of reversible norepinephrineinduced acute renal failure. Kidney Int 19:399-409

33. Noiri E, Peresleni T, Miller F, Goligorsky MS (1996) In vivo targeting of inducible NO synthase with oligodeoxynucleotides protects rat kidney against ischemia. J Clin Invest 97:2377-2383

34. Kwon O, Hong SM, Ramesh G (2009) Diminished NO generation by injured endothelium and loss of macula densa nNOS may contribute to sustained acute kidney injury after ischemia-reperfusion. Am J Physiol Renal Physiol 296:F25-33

35. Wilcox CS (2005) Oxidative stress and nitric oxide deficiency in the kidney: a critical link to hypertension? Am J Physio Regul Integr Comp Physiol 289:R913-935

36. Conesa EL, Valero F, Nadal JC, Fenoy FJ, Lopez B, Arregui B, Salom MG (2001) N-acetyl-L-cysteine improves renal medullary hypoperfusion in acute renal failure. Am J Physiol Regul Integr Comp Physiol 281:R730-737

37. Redfors B, Bragadottir G, Sellgren J, Sward K, Ricksten SE (2010) Acute renal failure is NOT an "acute renal success" - a clinical study on the renal oxygen supply/demand relationship in acute kidney injury. Crit Care Med 38:1695-1701

38. Singh P, Ricksten SE, Bragadottir G, Redfors B, Nordquist L (2013) Renal oxygenation and haemodynamics in acute kidney injury and chronic kidney disease. Clin Exp Pharmacol Physiol 40:138-147

39. Mandel LJ (1986) Primary active sodium transport, oxygen consumption, and ATP: coupling and regulation. Kidney Int 29:3-9

40. Molitoris BA, Falk SA, Dahl RH (1989) Ischemia-induced loss of epithelial polarity. Role of the tight junction. J Clin Invest 84:1334-1339

41. Molitoris BA, Wagner MC (1996) Surface membrane polarity of proximal tubular cells: alterations as a basis for malfunction. Kidney Int 49:1592-1597

42. Laycock SK, Vogel T, Forfia PR, Tuzman J, Xu X, Ochoa M, Thompson Cl, Nasjletti A, Hintze TH (1998) Role of nitric oxide in the control of renal oxygen consumption and the regulation of chemical work in the kidney. Circ Res 82 1263-1271

43. Borutaite V, Brown GC (1996) Rapid reduction of nitric oxide by mitochondria, and reversible inhibition of mitochondrial respiration by nitric oxide. Biochem J 315(Pt 1):295-299

44. Deng A, Tang T, Singh P, Wang C, Satriano J, Thomson SC, Blantz RC (2009) Regulation of oxygen utilization by angiotensin II in chronic kidney disease. Kidney Int 75:197-204

45. Aksu U, Ergin B, Bezemer R, Kandil A, Milstein DM, Demirci-Tansel C, Ince C (2015) Scavenging reactive oxygen species using tempol in the acute phase of renal ischemia/reperfusion and its effects on kidney oxygenation and nitric oxide levels. Intensive Care Med Exp 3:57

46. Wright RO, Lewander WJ, Woolf AD (1999) Methemoglobinemia: etiology, pharmacology, and clinical management. Ann Emerg Med 34:646-656

47. Anderson CM, Woodside KJ, Spencer TA, Hunter GC (2004) Methemoglobinemia: an unusual cause of postoperative cyanosis. J Vasc Surg 39:686-690

48. Nakajima W, Ishida A, Arai H, Takada G (1997) Methaemoglobinaemia after inhalation of nitric oxide in infant with pulmonary hypertension. Lancet 350:1002-1003

49. Maiden MJ, Otto S, Brealey JK, Finnis ME, Chapman MJ, Kuchel TR, Nash CH, Edwards J, Bellomo R (2016) Structure and function of the kidney in septic shock. A prospective controlled experimental study. Am J Respir Crit Care Med 194:692-700

50. Sinha SS, Shiva S, Gladwin MT (2008) Myocardial protection by nitrite: evidence that this reperfusion therapeutic will not be lost in translation. Trends Cardiovasc Med 18:163-172

51. Tripatara P, Patel NS, Webb A, Rathod K, Lecomte FM, Mazzon E, Cuzzocrea S, Yaqoob MM, Ahluwalia A, Thiemermann C (2007) Nitrite-derived nitric oxide protects the rat kidney against ischemia/reperfusion injury in vivo: role for xanthine oxidoreductase. J Am Soc Nephrol 18:570-580

52. Basireddy M, Isbell TS, Teng X, Patel RP, Agarwal A (2006) Effects of sodium nitrite on ischemia-reperfusion injury in the rat kidney. Am J Physiol Renal Physiol 290:F779-786

53. Frithiof R, Soehnlein O, Eriksson S, Fenhammar J, Hjelmqvist H, Lindbom L, Rundgren M (2011) The effects of isoflurane anesthesia and mechanical ventilation on renal function during endotoxemia. Acta Anaesthesiol Scand 55:401-410

54. Frithiof R, Eriksson S, Bayard F, Svensson T, Rundgren M (2007) Intravenous hypertonic NaCl acts via cerebral sodiumsensitive and angiotensinergic mechanisms to improve cardiac function in haemorrhaged conscious sheep. J Physiol 583:1129-1143 